\title{
ASSESSMENT OF BONE REGENERATION OF CRITICAL SIZE MANDIBULAR DEFECTS USING ADIPOSE DERIVED STEM CELLS: AN EXPERIMENTAL COMPARATIVE STUDY
}

Shereen Wagdy Arafat *, Samah Mohamed Kamel ${ }^{* *}$, Ahmed Mohamed Hossam ${ }^{* * *}$ and Dina Sabry ****

\begin{abstract}
Objectives: this study was to assess the effect of adipose derived stem cells on bone regeneration of mandibular defects of rabbits.

Material and methods: Twenty four adult male New Zealand white rabbits were divided into two groups. Group A (control group) in which surgically created critical size mandibular defects were created and left to heal without grafting. Group B (test/stem group) from which adipose tissue was withdrawn and stem cells were processed and then seeded on the gel-foam scaffold to be grafted in the surgically created critical size mandibular defects. The treatment outcome was evaluated at 2, 4, 8 weeks postoperatively both radiographically and histologically. Mineralization ratio was statistically analyzed.
\end{abstract}

Results: histologic and radiographic evaluation revealed significant $(\mathrm{p} \leq 0.05)$ enhancement of bone regeneration at test group (A) as compared to control group (B).

Conclusion: the use Adipose derived mesenchymal stem cells proved to be effective for enhancing bone regeneration in mandibular critical-size bone defects.

KEY WORDS: stem cells, adipose tissue, mandibular defects, bone healing.

\section{INTRODUCTION}

One of the major surgical challenges in oral and maxillofacial field has been the reconstruction of bony defects. ${ }^{(1)}$ Mandibular defects that resulted from a variety of pathologic processes are common problems encountered by the oral and maxillofacial surgeons. ${ }^{(2)}$ Bone grafting represents a frequently performed procedure to enhance bone regeneration in these defects. Autologous bone graft is consid-

* Lecturer, Department of Oral and Maxillofacial Surgery, Faculty of Dentistry, October University of Modern Sciences and Art.

** Lecturer, Department of Oral Biology, Faculty of Dentistry, October University of Modern Sciences and Art.

*** Lecturer, Department of Oral Radiology, Faculty of Dentistry, October University of Modern Sciences and Art. ***** Professor, Department of Medical Biochemistry and Molecular Biology, Faculty of Medicine, Cairo University 
ered the gold standard bone grafting material. However, its harvesting is associated with donor-site morbidity and restricted availability. ${ }^{(3,4)}$ Moreover, the alternative use of allografts has high cost, potential immunogenic response by the host to the foreign tissue, and possibility of disease transmission. ${ }^{(5)}$ Tissue engineering of bone via genetically modified stem cells has been viewed as a potential alternative to the conventional bone grafts for repairing bone defects. ${ }^{(6-8)}$ Mesenchymal stem cells (MSCs) are non-hematopoietic pleuripotent stromal cells that reside in various solid organs as well as in bone marrow and adipose tissue. ${ }^{(9)}$ Adipose-derived stem cells were first identified in 1980s, and appears to be a promising candidate for osseous reconstruction because of their abundant volume and the ease with which they are obtained. ${ }^{(10,11)}$ Moreover, it can undergo rapid and efficient osteogenic differentiation in vitro. ${ }^{(12,13)}$

Gel Foam is a gelatin-based sponge used during and after surgical procedures as wound dressing and to control bleeding. Gel Foam was used as a scaffold for stem cells in many experimental studies, and showed very good biocompatibility without any immune response. ${ }^{(14)}$ Moreover, Gel Foam was used in bone defects after removal of cysts in humans, and the residuals of gelatin sponge were incorporated in the new bone, without showing any significant foreign-body reaction. ${ }^{(15)}$

The rabbit is a mammal that is biologically similar to the human and has been recognized as an appropriate model to study bone regeneration in the maxillofacial region. Numerous studies were conducted to evaluate mandibular bone defects repair in rabbits with a defect design at the lower border without loss of mandibular continuity. ${ }^{(16-18)}$

The reconstruction of a critical-size defect at preclinical trials level has been limited. Therefore, this study was conducted to evaluate the reconstruction of critical-size mandibular defects in the rabbit model using adipose tissue stem cells both histologically and radiographically.

\section{MATERIALS AND METHODS}

Twenty four adult male New Zealand white rabbits in healthy conditions, aged 5-6 months, with average weight ranging from 2.5 to $4 \mathrm{~kg}$ were involved in the current study. The rabbits were under veterinary supervision in an animal house. The rabbits were randomly divided into 2 groups of 12 animals each. Group (A) comprised the control group and group (B) comprised the stem cell/test group. The study was conducted in two phases for group (B). In the first phase (harvest phase), adipose tissue was collected under general anesthesia by 1 $\mathrm{cm}$ skin incision under the chin of each rabbit of this group.

\section{Mesenchymal stem cells isolation and osteogenic differentiation}

The collected adipose tissue was resected and washed in $15 \mathrm{ml}$ phosphate buffered solution (PBS; Gibco/Invitrogen, Grand Island, New York, USA). Enzymatic digestion was performed using $0.03 \%$ collagenase II (Serva Electrophoresis $\mathrm{GmbH}$, Mannheim) in Hank's Balanced Salt Solution for 60 minutes at $37^{\circ} \mathrm{C}$ with continuous shaking. Digested tissue was strained, centrifuged, and erythrocytes were removed by treatment with erythrocyte lysis buffer. The filtered cells were transferred to tissue culture flasks with RPMI 1640 (Gibco/BRL, Grand Island, New York, USA) supplemented with $10 \%$ fetal bovine serum (Gibco/BRL), 1\% Penicillin with Streptomycin(Gibco/BRL) and after an attachment period of 24 hours, non-adherent cells were removed by a PBS wash. Attached cells were cultured and expanded in vitro for 10-14 days with changing media every 3 days (passage 0 ). On developing large colonies (80 90\% confluence), cultures were washed twice with PBS and the cells were trypsinized with $0.25 \%$ trypsin in $1 \mathrm{mM}$ EDTA (Gibco/BRL) for $5 \mathrm{~min}$ at $37^{\circ} \mathrm{C}$. After centrifugation, cells were suspended with serum-supplemented medium and incubated in $50 \mathrm{~cm}^{2}$ culture flask (Falcon). The resulting cultures were referred to as first-passage cultures and expanded in vitro until 
passage three. ${ }^{(19)}$ For differentiation of MSC into osteocytes, passage $3 \mathrm{MSCs}$ were cultured at a density of $4.2 \times 10^{3}$ cells $/ \mathrm{cm}^{2}$ with $0.5 \mathrm{ml}$ osteogenic differentiation medium (R\&D Systems) to induce osteogenesis. Osteocytes then were fixed and stained with Alizarin Red (Sigma-Aldrich) and photographed using a photomicroscope. (20) Fig. $(1 \mathrm{~A}, 1 \mathrm{~B})$

\section{Surgical procedure}

All the rabbits included in this study underwent surgical procedures under aseptic conditions by the same surgeon under general anesthesia, which was induced by injection of ketamine hydrochloride (45$50 \mathrm{mg} / \mathrm{kg}$ ) combined with xylazine hydrochloride (5-7 $\mathrm{mg} / \mathrm{kg}$ ) intramuscularly. The surgical region was shaved, and the skin was prepared with $10 \%$ povidone iodine antiseptic solution. Local anaesthesia with vasoconstrictor was administered at the surgical site, then a $2-3 \mathrm{~cm}$ skin incision was made about $1 \mathrm{~cm}$ below the lower border of mandibular body region. Blunt dissection and periosteum excision was performed to exclude the periosteum osteogenesis effect. A mono-cortical 10 mm diameter defect was created using a surgical round bur at low speed under copious irrigation. The defects were made at the mandibular body region, and did not interrupt the mandibular continuity. Fig. (2A)

Twelve surgically created defects were left empty as control group (A). Twelve surgically created defects of group (B) were filled with Gel Foam seeded with the previously prepared Adipose Derived Stem Cells. Fig. (2B, 2C) The Gel Foam was secured in place by means of suturing muscles, subcutaneous tissue, and skin in layers.

The animals were sacrificed as 3 rabbits of each group at 2 and 4 weeks postoperatively for histologic assessment of healing, while at 8 weeks, the remaining 6 rabbits in each group were sacrificed for histologic and radiologic assessment using an overdose of I.V. Phenobarbital.

\section{Radiological examination}

The radiographic scans were obtained using CBCT Newtom GIANO/VG3- (Quantitative Radiology, Imola, Italy). Under general anesthesia, the rabbits were centered and fixed in the CBCT system. They were positioned according to the recommendations of the $\mathrm{CBCT}$ manufacturer. The midline laser beam of the CBCT system was adjusted to the mid-sagittal plane of the skull. The horizontal laser beam was parallel to the occlusal plane. The rabbits in each group were assigned to bone healing evaluation at 2,4 , and 8 weeks pstoperatively. Each rabbit was scanned a full high resolution scan: Voxel size $0.125 \mathrm{~mm}(27 \mathrm{mAs}, 90$ $\mathrm{kVp}, 3 \mathrm{~mA})$ and a field of view (FOV) of $80(\mathrm{~mm})$ $\times 80(\mathrm{~mm}), 360^{\circ}$ rotation around patients in 9-second scan time.

Obtained data was converted into Digital Imaging and Communications in Medicine (DICOM) format, and was imported into the software (Newtom GIANO/VG3-Annex, version 7.2, Imola, Italy) for volumetric analysis. The images were displayed in all 3 orthogonal planes (axial, coronal, and sagittal). A panoramic reconstruction of the volume was created, and cross-sectional images of the region of interest were generated with a pitch distance of $1 \mathrm{~mm}$ and a slice thickness of $1 \mathrm{~mm}$. Fig. (3)

In order to compare the density of the regenerated bone within the defects of the test group at the three selected evaluation periods, it was of great importance to measure the normal density base line for each case. Given the density of the opposite side (normal side) as a base line reference for each case, the mineralization ratio (density ratio) was the ratio between the average bone density of the defect area and the average bone density of the normal side using Hounsfield Unit ratio. Fig. (4)

\section{Histologic preparation}

A histological sample was taken from each group within the region of bone regeneration 
in the mandible. Samples were fixed with $10 \%$ neutral formalin, embedded in paraffin after decalcification, and stained with Hematoxylin and Eosin (H\&E) as a Routine stain for cellular details. In addition, Toluidine blue Stain was utilized for optimal demonstration of mineralized bone and osteoid seams. Furthermore, Masson's trichrome stain was utilized for differentiation of mineralized and non-mineralized areas in bone. Histological and histochemical staining were performed for both groups at postoperative 2, 4 and 8 weeks. All Stained specimens were inspected by the naked eye and under the microscope.

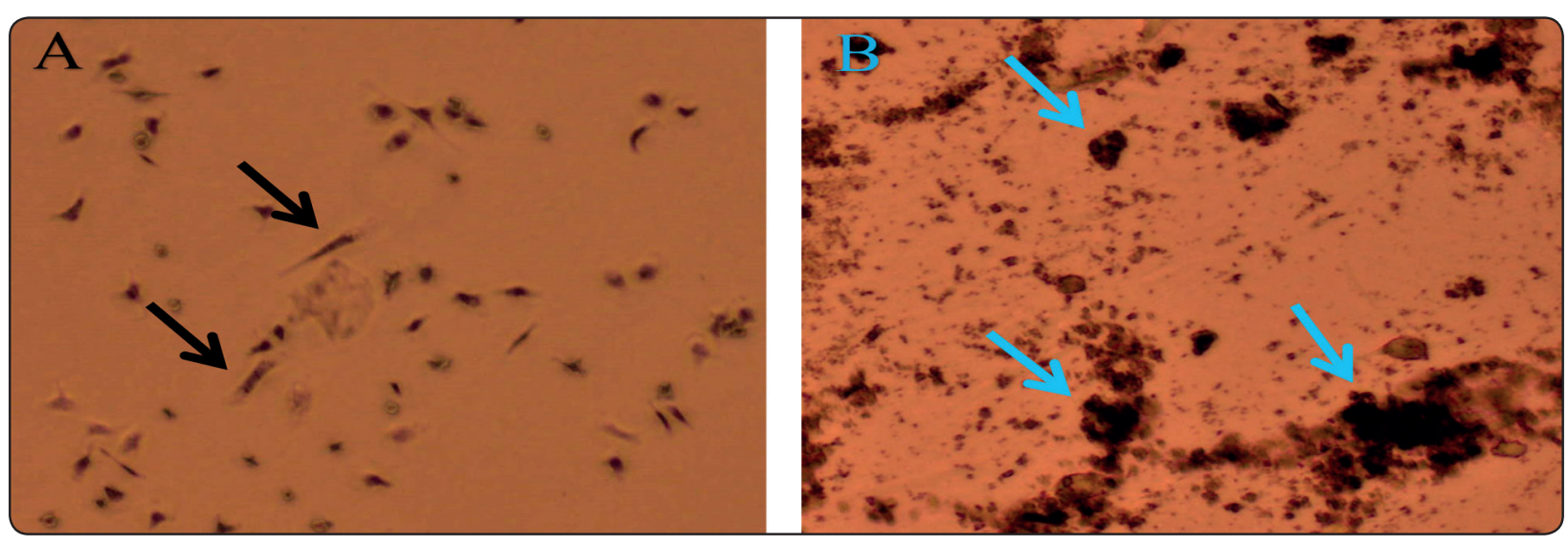

Fig. (1) A) MSCs were expanded in culture for 21 days. They were identified by their fusiform fibroblast like cells (black arrow), B) MSCs were differentiated into osteocyte in culture at passage 3. Osteocyte were stained with Alzarin Red (blue arrow) for identification
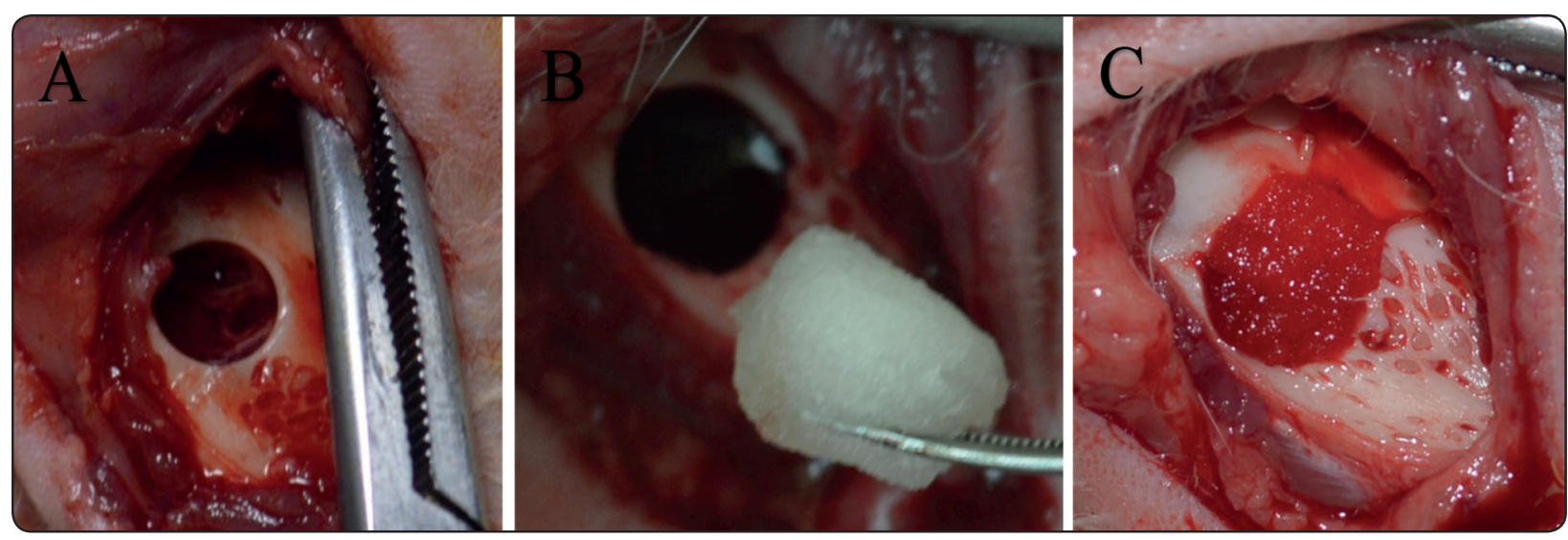

Fig. (2) A) Critical size defect $15 \mathrm{~mm}$ diameter created on the lateral aspect of the body of the mandible, B) Gel-Foam seeded with Adipose Derived Stem Cells (ADSC), C) The created bony defect filled with the ADSC seeded on the Gel Foam. 


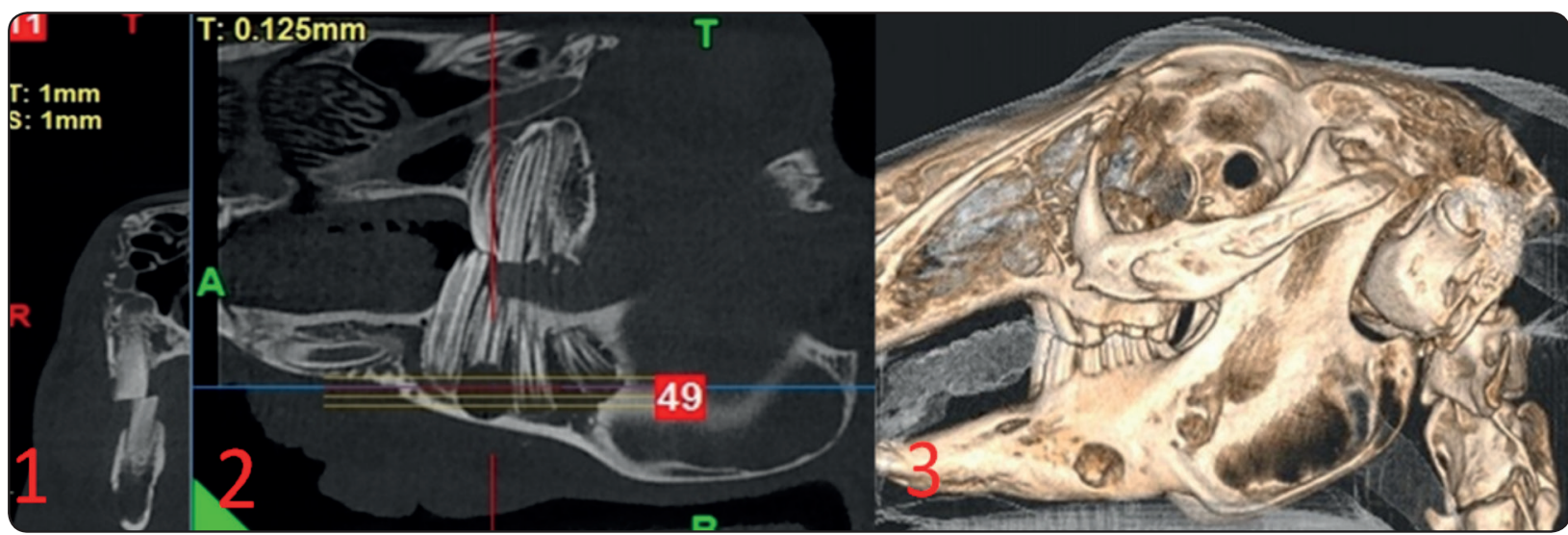

Fig.(3) CBCT immediately postoperative, 1\&2) Coronal \& Sagittal view of the imposed defect, 3) Three-dimensional computed tomography radiographic images of imposed defect.

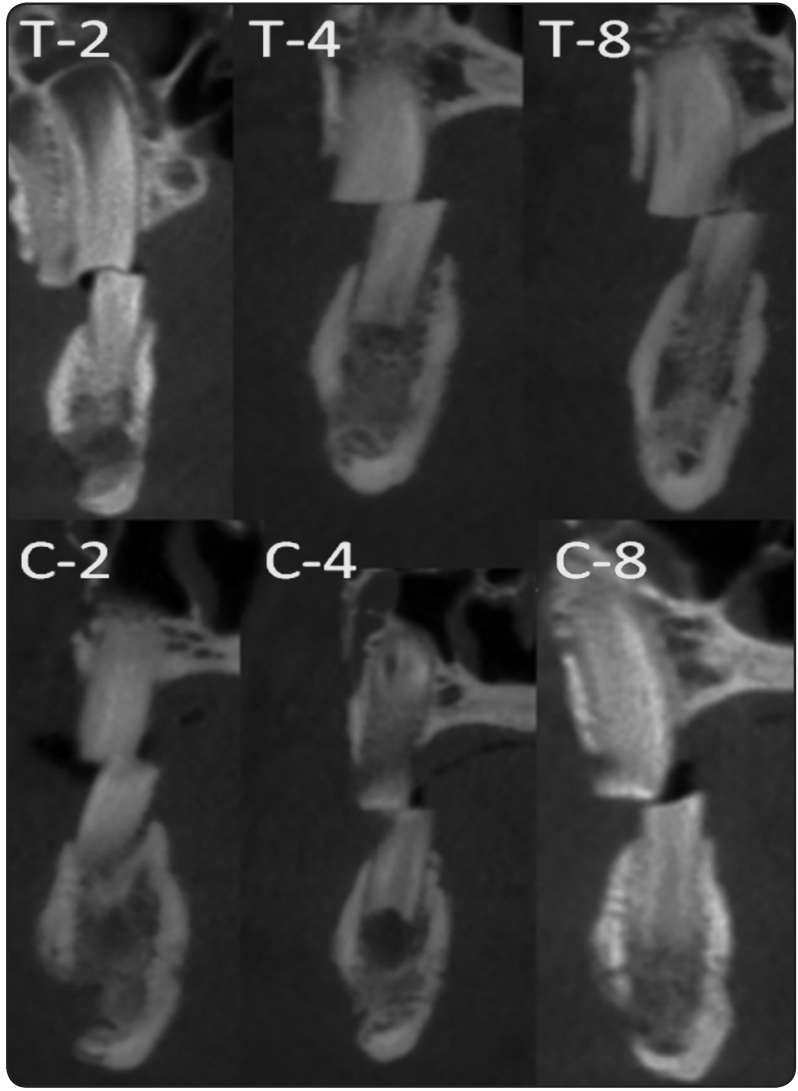

Fig. (4) CBCT evaluation of the test group (T-) and control group (C-) cases at the 2-, 4-, and 8-weeks intervals represented as T-2,T-4,T-8 for the test group and C-2,C$4, \mathrm{C}-8$ for the control group.

\section{RESULTS}

During the follow-up period of eight weeks, there were no signs of infection, and rabbits returned to normal food intake within 3-4 days after surgery. No complications were encountered in cell collection, and no animal was lost during the study.

Regarding the mean bone density, there was nonsignificant difference $(\mathrm{p} \geq 0.05)$ between the mean bone densities in the two groups pre-operatively. At 2 weeks postoperatively, the Control group showed significant higher $(\mathrm{p} \leq 0.05)$ mean values of mineralization ratio (density ratio) than that of the test group. While, at 4 , and 8 weeks interval, the test group showed significant higher $(p \leq 0.05)$ mean values of mineralization ratio (density ratio) than that of the control group. Fig. (5)

Regarding the mineralization ratio (density ratio) within each group, it was found that the mineralization ratio of the test group was slow at 2 weeks postoperatively, while it showed significant increase $(\mathrm{p} \leq 0.05)$ in bone mineralization ratio at 4 weeks postoperatively, then the bone mineralization ratio significantly decreased $(\mathrm{p} \leq 0.05)$ at the $8^{\text {th }}$ week postoperatively. While, the control group mineralization ratio was high at 2 weeks postoperatively, then this ratio significantly $(\mathrm{p} \leq 0.05)$ decreased at the $4^{\text {th }}$, and $8^{\text {th }}$ week postoperatively. (Fig.6) 


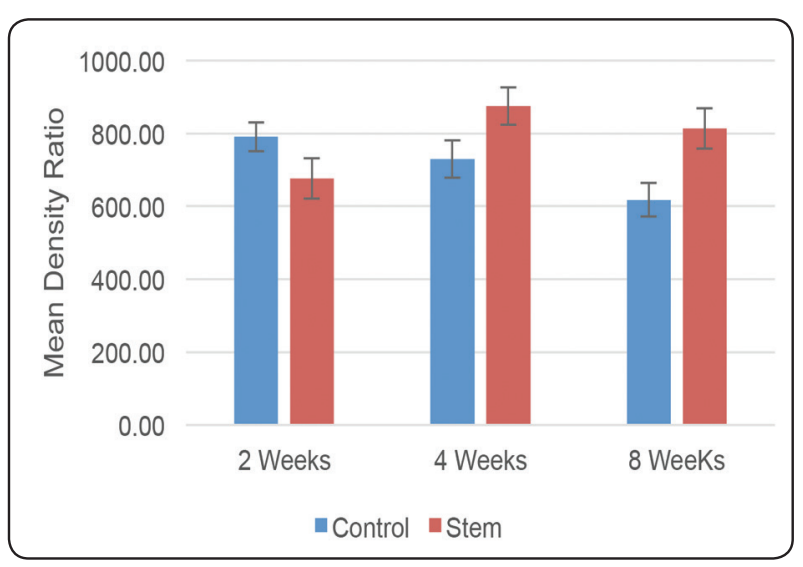

Fig. (5) Bar chart showing mean Density Ratio for the study groups

\section{Histologic \& Histochemical evaluation:}

Regarding H\&E stain evaluation, it was found that in the second week post operatively healing of bone was noticed in both groups with formation of granulation tissue and multiple large osteoid tissues. The healing process in the control group was better than that of the test group as more osteoid tissues and less granulation tissue appeared in group A. Fig. (7)

In the fourth week, the healing process continued as the granulation tissue completely disappeared in both groups and the osteoid tissues were partially replaced with mature bone. The healing process in control group was less than test group. Many reversal lines were noticed in test group denoting maturation of bone. Fig. (8)

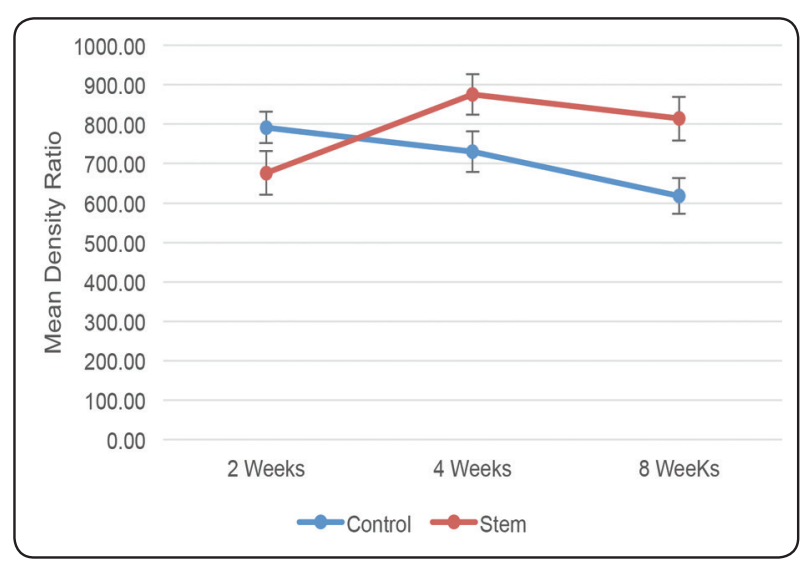

Fig. (6) Line chart showing the increase on mean Density Ratio for follow-up periods for each group.

In the 8th week, the bone defects in both groups were healed, complete maturation of bone in the test group was noticed while control group still has small scattered osteoid tissue. Fig. (9)

Regarding Toluidine blue staining, the osteoid tissue was noticed in the second week in both groups. The maturation of bone was faster in the test group than in the control group as in the 8th week post operatively group B showed complete maturation. (Fig. 10)

Regarding Goldner's Masson Trichrome stain, its use in both groups (A\&B) demonstrated clear differentiation between mineralized mature bone that stained blue or green and un-mineralized new immature bone that stained red. Fig. (11) 


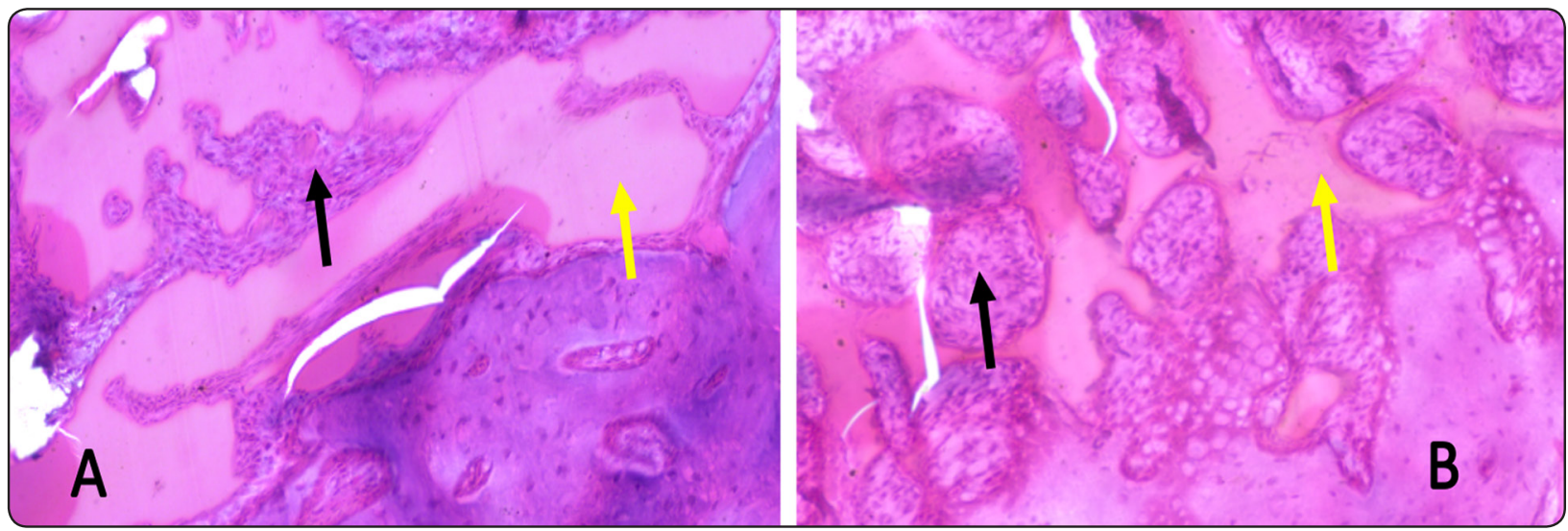

Fig. (7) A) photomicrograph of control group showing granulation tissue (black arrow) and uncalcified osteoid tissues (yellow arrow), B) the section of test group showing less osteoid tissue separated with granulation tissue (H\&E X200).

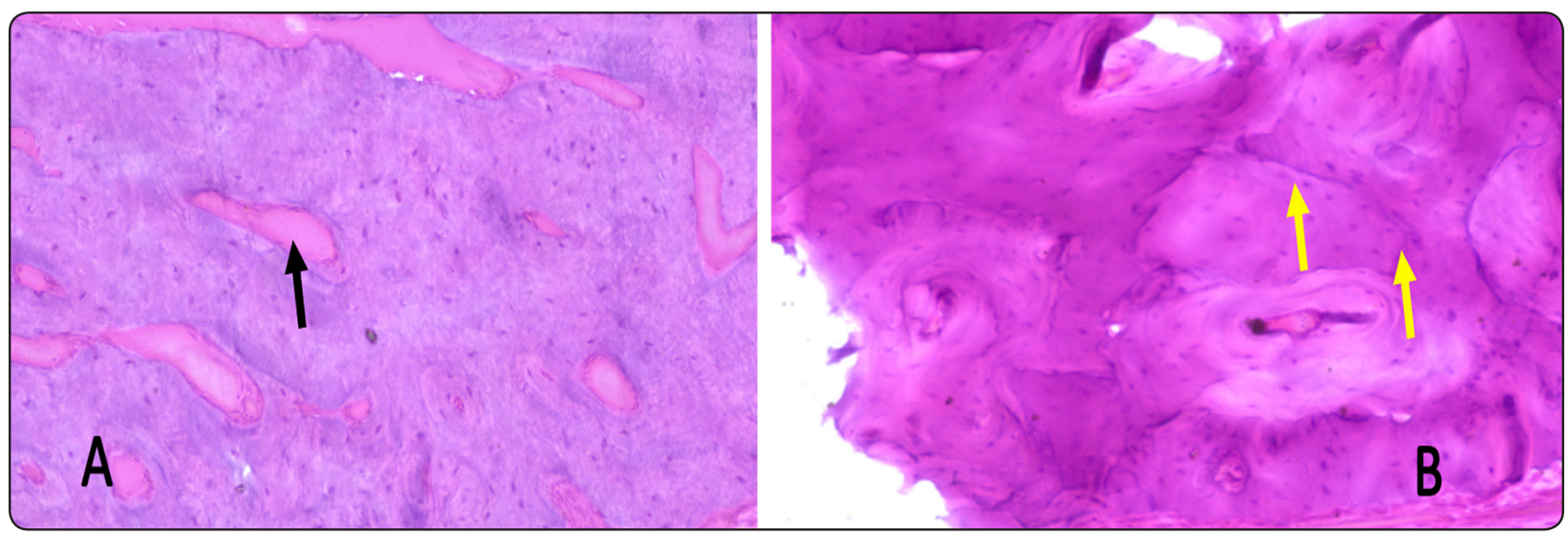

Fig. (8) A) photomicrograph showing scattered small osteoid tissues (black arrow), B) the section showing newly formed Haversian systems with many reversal lines (yellow arrow)( H\&E X200)

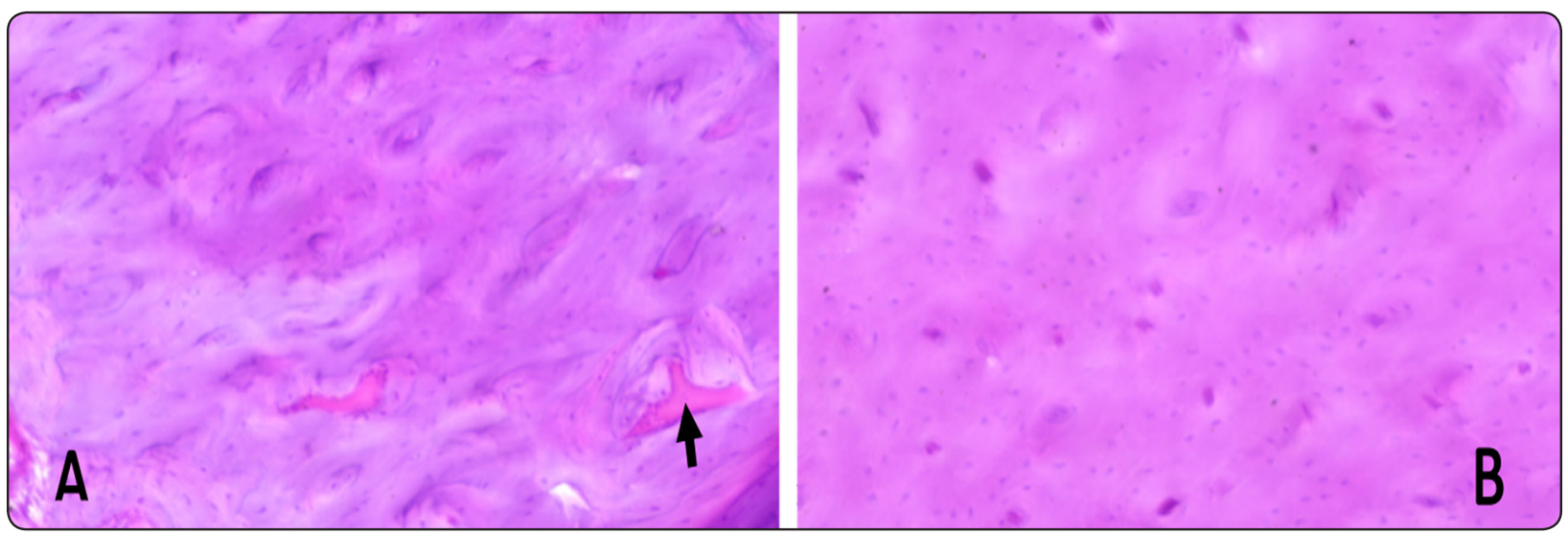

Fig. (9) (A) photomicrograph of control group showing newly formed Haversian systems with few osteoid tissues (black arrow) (B) the section of test group showing fully formed Haversian systems (H\&E X200) 


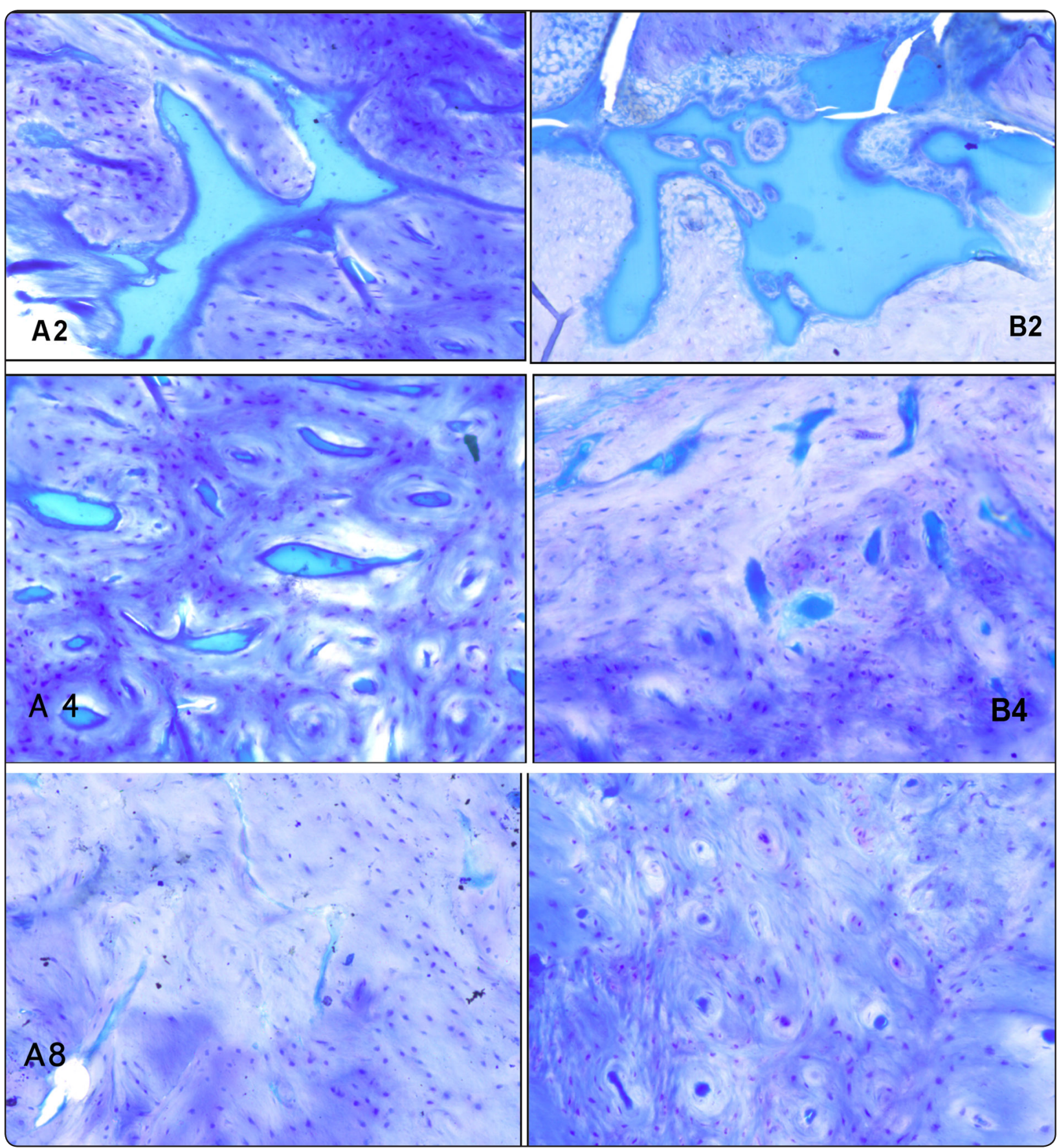

Fig. (10) A2, B2) photomicrograph showing osteoid tissues in the wound areas after 2 weeks, A4, B4) the sections were examined after 4 weeks, maturation of bone and formation of lamellar bone were detected in both groups but in group A the maturation was less than group B. In (A8, B8) complete maturation of bone after 8 weeks in group B, while in group A there are still remnants of osteoid tissues. (Toluidine blue X200) 


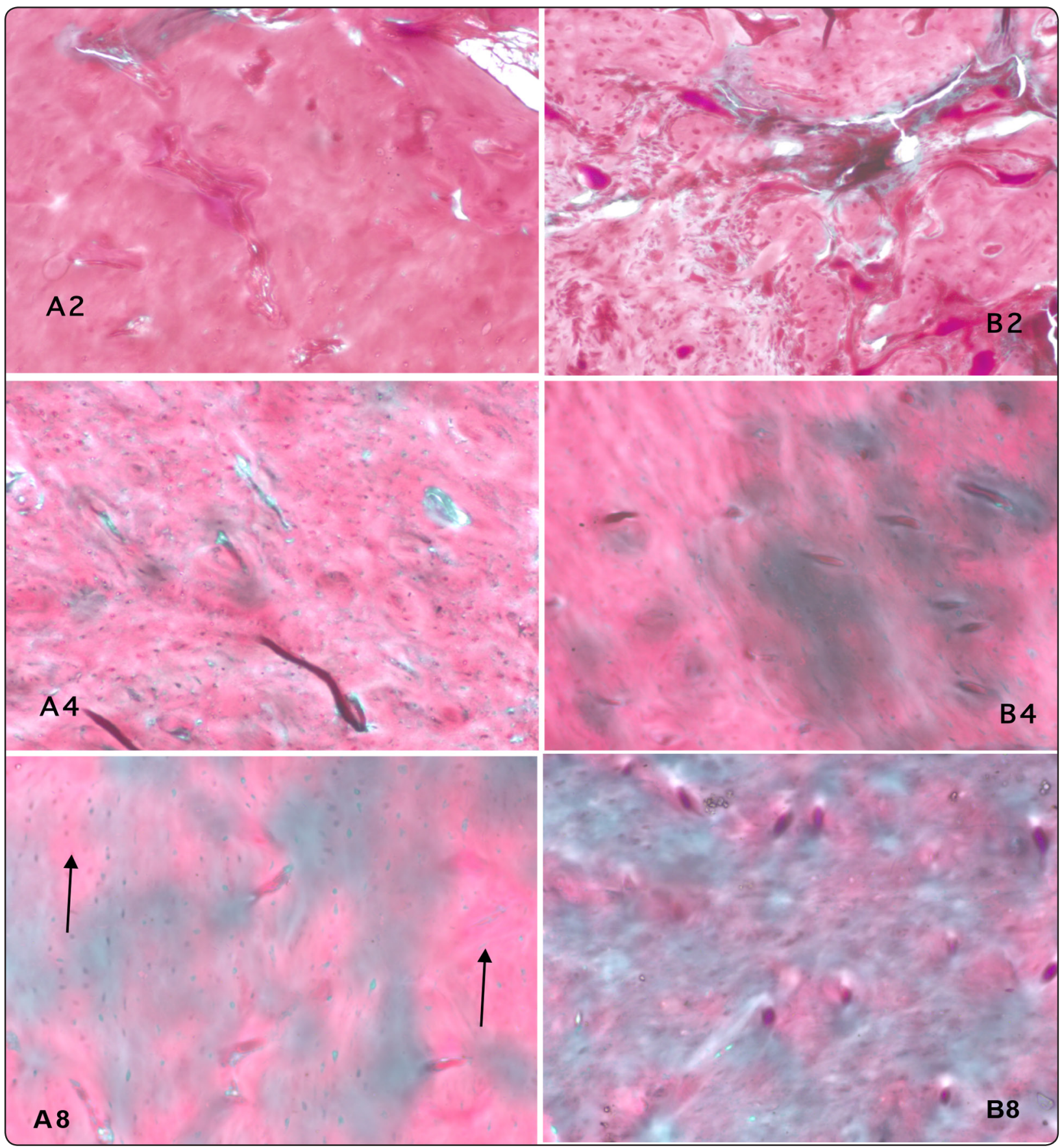

Fig. (11) A2, B2) photomicrograph showing no calcifications can be detected after 2 weeks in both groups, A4,B4) the sections were examined after 4 weeks, calcification of was detected in both groups but in group A the calcification was less than group B.(Masson X200), A8, B8) showing complete calcification of group B , un calcified bone is still present in group A ( Black arrows). 


\section{DISCUSSION}

The outcomes of this study confirmed that the rabbit is a good model for the assessment of bone healing of mandibular critical-size defect. The animals returned to normal function a few days after surgery which could help the bone remodeling process. This agrees with $\mathrm{Lu}$ and Rabie, 2002. ${ }^{(16)}$ Rabbits in the current study were evaluated at 2, 4, and 8 weeks both radiographically, and histologically. This allowed us to assess the early events in bone regeneration, and the long term follow-up of the bone defects of the study groups. This agrees with the study of Miloro et al., 2010. ${ }^{(21)}$

Histological evaluation of the regenerated tissues within the experimental defects revealed that bone regeneration at 2 weeks postoperatively was better in the control group than in the test group. This could be attributed to the rapid formation of the embryonic bone in the non-grafted cavity defect which was later resorbed and replaced by regenerated bone. Moreover, the scaffold degradation to be subsequently replaced by new bone at the test group may explain this finding. While at 4 weeks postoperatively, the test group bone regeneration reaches its peak with homogenous distribution of regenerated bone, which was much better than the control group. At 8 weeks postoperatively, the process of mineralization continues in the two groups with better bone regeneration at the test group. These findings are in agreement with the previous report of Kon et al, 2000. ${ }^{(22)}$

Radiographic evaluation and statistical analysis of the mineralization ratio (density ratio) supports the histologic results as the significant difference reported at 2 weeks in favor of the control group then significant difference in favor of the test group in mineralization ratio at 4 and 8 weeks postoperatively.

The results of our study showed that adipose derived stem cells enhanced bone regeneration and mineralization in the test group as compared with the control group at 4 and 8 weeks postoperatively. This could be attributed to the conversion of mesenchymal stem cells into osteoblasts, as reported by Jang et al., 2008, ${ }^{(23)}$ and Jiang et al., 2010. ${ }^{(24)}$ Moreover, These results are in agreement with several previous studies. ${ }^{(25-30)}$

On the other hand, Dudas, et al ${ }^{(31)}$ in 2006 reported no added value of adipose derived stem cells on bone regeneration. This could be attributed to the small sample size, and non-critical size defects in their study. A defect is considered a critical size when no spontaneous complete osseous regeneration occurs during the lifetime of the animal. ${ }^{(31,32)}$

In our study, we used non-mineralized gelfoam scaffold, and mineralization was properly achieved. This could be attributed to the pre-existing growth factors present in the host bone defect, and the transplanted stem cells which may produce cytokines and chemokines. This result agrees with other studies ${ }^{(33-35)}$, and contradict with that of Hattori et al., ${ }^{(10)} 2006$ who reported the necessity of mineralized scaffolds to achieve favorable results regarding the differentiation of adipose derived stem cells.

\section{CONCLUSION}

Adipose derived mesenchymal stem cells were proved to be an effective, simple, and safe method for enhancing bone regeneration in mandibular critical-size bone defects.

\section{REFERENCES}

1. Schliephake H, Weich HA, Dullin C, Gruber R, Frahse S. Mandibular bone repair by implantation of rhBMP-2 in a slow release carrier of polylactic acid: an experimental study in rats. Biomaterials; 29: 103-110, 2008.

2. Huh JY, Choi BH, Kim BY, Lee SH, Zhu SJ, Jung JH. Critical size defect in the canine mandible. Oral Surg Oral Med Oral Pathol Oral Radiol Endod; 3: 296-301, 2005.

3. Ahlmann E, Patzakis M, Roidis N, Shepherd L, Holtom P. Comparison of anterior and posterior iliac crest bone 
grafts in terms of harvest-site morbidity and functional outcomes. J Bone Joint Surg Am; 5: 716-720, 2002.

4. Dinopoulos H, Dimitriou R, Giannoudis PV. Bone graft substitutes: what are the options? Surgeon; 4:230-239, 2012.

5. Greenwald AS, Boden SD, Goldberg VM, Khan Y, Laurencin CT, Rosier RN. Bone-graft substitutes: facts, fictions, and applications. J Bone Joint Surg Am; 83: 98-103, 2001.

6. Qu D, Li J, Li Y. Angiogenesis and osteogenesis enhanced by bFGF ex vivo gene therapy for bone tissue engineering in reconstruction of calvarial defects. J Biomed Mater Res; 96: 543-551, 2011.

7. Zhang Y, Wu C, Luo T, Li S, Cheng X, Miron RJ. Synthesis and inflammatory response of a novel silk fibroin scaffold containing BMP7 adenovirus for bone regeneration. Bone; 51: 704-713,2012.

8. Zhu C, Chang Q, Zou D. LvBMP-2 gene-modified BMSCs combined with calcium phosphate cement scaffolds for the repair of calvarial defects in rats. J Mater Sci Mater Med; 22: 1965-1973,2011.

9. J.K. Fraser, I. Wulur, Z. Alfonso, M.H. Hedrick. Fat tissue: an underappreciated source of stem cells for biotechnology. Trends Biotechnol; 24: 150-154, 2006.

10. Hattori H, Masuoka K, Sato M. Bone formation using human adipose tissue-derived stromal cells and a biodegradable scaffold. J Biomed Mater Res B Appl Biomater; 76: 230-239, 2006.

11. Crisan M, Casteilla L, Lehr L . A reservoir of brown adipocyte progenitors in human skeletal muscle. Stem Cells; 26: 2425-2433,2008.

12. Sterodimas A, Faria J, Nicaretta B, Pitanguy I. Tissue engineering with adipose-derived stem cells (ADSCs): current and future applications. J. Plast. Reconstr. Aesthet. Surg; 63:1886-1892,2010.

13. Boeloni J, Ocarino N, Goes A, Serakides R. Comparative study of osteogenic differentiation potential of mesenchymal stem cells derived from bone marrow and adipose tissue of osteoporotic female rats. Connect Tissue Res; 55 : 103-114, 2014.

14. Bilsouva G, Jun D H, King K. Osteoblasts Derived from Induced Pluripotent Stem Cells form Calcified Structures in Scaffolds Both In Vitro and In Vivo. Stem Cells; 29: 206-216, 2011.
15. Rohanizadeh R, Swain M V, Mason R. Gelatin Sponges (Gel foam) as a scaffold for osteoblasts. J Mater Sci ; 19:1173-1182, 2008.

16. Lu M, Rabie AB. The effect of demineralized intramembranous bone matrix and basic fibroblast growth factor on the healing of allogeneic intramembranous bone grafts in the rabbit. Arch Oral Biol; 47: 831-841, 2002.

17. Lu M, Rabie AB: Microarchitecture of rabbit mandibular defects grafted with intramembranous or endochondral bone shown by micro-computed tomography. $\mathrm{Br} \mathrm{J}$ Oral Maxillofac Surg; 41: 385-391, 2003.

18. Busuttil N K, Ayoub A, McMahon J, Di Silvio L, Lappin $\mathrm{D}$, Hunter KD. Mandibular reconstruction in the rabbit using beta-tricalcium phosphate (beta-TCP) scaffolding and recombinant bone morphogenetic protein 7 (rhBMP-7) e histological, radiographic and mechanical evaluations. J Craniomaxillofac Surg; 40: 461-469, 2012.

19. Dizaji Asl K, Shafaei H, Soleimani Rad J, Nozad HO. Comparison of Characteristics of Human Amniotic Membrane and Human Adipose Tissue Derived Mesenchymal Stem Cells. World J Plast Surg ;6:33-39, 2017.

20. Zayed SA, Gaafar TM, Samy RM, Sabry D, Nasr AS, Maksoud FA. Production of endothelial progenitor cells obtained from human Wharton's jelly using different culture conditions. Biotech Histochem; 91:532-539, 2016.

21. Miloro M, Haralson DJ, Desa V. Bone healing in a rabbit mandibular defect using platelet-rich plasma. J Oral Maxillofac Surg; 68: 1225-1230, 2010.

22. Kon E, Muraglia A, Corsi A, Bianco P, Marcacci M, Martin I. Autologous bone marrow stromal cells loaded onto porous hydroxyapatite ceramic accelerate bone repair in critical-size defects of sheep long bones. J Biomed Mater Res; 49: 328-337, 2000.

23. Jang BJ, Byeon YE, Lim JH, Ryu HH, Kim WH, Koyama Y. Implantation of canine umbilical cord blood-derived mesenchymal stem cells mixed with beta-tricalcium phosphate enhances osteogenesis in bone defect model dogs. J Vet Sci; 9: 387-393, 2008.

24. Jiang X, Zou S, Ye B, Zhu S, Liu Y, Hu J. bFGF-Modified BMMSCs enhance bone regeneration following distraction osteogenesis in rabbits. Bone; 46: 1156-1161, 2010.

25. Lei Cui, Bo Liu, Guangpeng Liu, Wenjie Zhang, Lian Cen, Jian Sun, Shuo Yin, Wei Liu, Yilin Cao. Repair of cranial bone defects with adipose derived stem cells and coral scaffold in a canine model. Biomaterials; 28: 5477-5486. 
26. Kim HP1, Ji YH, Rhee SC, Dhong ES, Park SH, Yoon ES. Enhancement of bone regeneration using osteogenic-induced adipose-derived stem cells combined with demineralized bone matrix in a rat critically-sized calvarial defect model. Curr Stem Cell Res; 7:165-172,2012.

27. Akita S, Fukui M, Nakagawa H, Fujii T, Akino K. Cranial bone defect healing is accelerated by mesenchymal stem cells induced by co-administration of bone morphogenetic protein-2 and basic fibroblast growth factor. Wound Repair Regen; 12: 252-259, 2004.

28. Yoon E, Dhar S, Chun DE, Gharibjanian NA, Evans GR: In vivo osteogenic potential of human adipose derived stem cells/poly lactide-co-glycolic acid constructs for bone regeneration in a rat critical-sized calvarial defect model. Tissue Eng; 13:619-627, 2007

29. Lin Y, Tang W, Wu L, JingW, Li X,Wu Y. Bone regeneration by BMP-2 enhanced adipose stem cells loading on alginate gel. Histochem Cell Biol; 129: 203-210, 2008.

30. Bohnenblust ME, Steigelman MB, Wang Q, Walker JA, Wang HT. An experimental design to study adipocyte stem cells for reconstruction of calvarial defects. J Craniofac Surg; 20: 340-346, 2009.

31. Dudas JR1, Marra KG, Cooper GM, Penascino VM, Mooney MP, Jiang S, Rubin JP, Losee JE. The osteogenic potential of adipose-derived stem cells for the repair of rabbit calvarial defects. Ann Plast Surg; 56:543-548, 2006

32. Schmitz JP, Hollinger JO. The critical size defect as an experimental model for cranio-mandibulofacial non-unions. Clin Orthop Relat Res; 205: 299-308, 1986.

33. Hollinger JO, Kleinschmidt JC. The critical size defect as an experimental model to test bone repair materials. J Craniofac Surg; 1: 60-68, 1990.

34. Frank O, Heim M, Jakob M, Barbero A, Scheafer D, Bendik I. Real-time quantitative RT-PCR analysis of human bone marrow stromal cells during osteogenic differentiation in vitro. J Cell Biochem; 85: 737-746, 2002.

35. Kapur SK, Katz AJ. Review of the adipose derived stem cell secretome. Biochimie; 95: 2222-2228, 2013. 